\title{
ENSINO MÉDIO, EDUCAÇÃO PROFISSIONAL E PROGRAMA BRASIL PROFISSIONALIZADO: ANÁLISES E TENSÕES PÓS LEI 9394/1996
}

\section{HIGH SCHOOL, PROFESSIONAL EDUCATION AND PROFESSIONAL BRAZIL PROGRAM: ANALYSIS AND TENSIONS AFTER LAW 9394/1996}

\author{
LEITE, Maria Cleide da Silva Ribeiro ${ }^{1}$ \\ ANDRADE, Francisca Rejane Bezerra²
}

\begin{abstract}
RESUMO
Este artigo objetivou investigar o impacto do Projeto Professor Diretor de Turma nas Escolas Profissionais para a Profissionalidade Docente do Ceará. O contexto cearense até o ano de 2007 ofertava somente o Ensino Médio na modalidade regular e em 2008, com a adesão ao Programa Brasil Profissionalizado, implantou o Ensino Médio integrado a Educação Profissional. Voltou-se ao ponto em tudo começou, decorridos dez anos das Escolas Profissionais, para investigar possíveis avanços, desafios e perspectivas futuras. Realizou-se uma pesquisa qualitativa, apoiada no Materialismo Dialético, por meio de um estudo de caso, com entrevista, observação, questionário e análise documental. Utilizou-se a Análise do Discurso Crítico. Os resultados revelaram a Educação Profissional como um divisor de água no Ensino Médio do Ceará. Concluiu-se que a flexibilização curricular particularizou especificidades às escolas profissionais, modificou a profissionalidade docente e a rotina estudantil.
\end{abstract}

Palavras-Chave: Ensino Médio; Programa Brasil Profissionalizado; Educação Profissional; Projeto Professor Diretor de Turma; Ceará.

\section{ABSTRACT}

This article aimed to investigate the impact of the Project Teacher Director of Class in the Professional Schools for Teaching Professionality of Ceará. The Ceará context until 2007 offered only high school in the regular mode and in 2008, with the adhesion to the Professionalized Brazil Program, implemented high school integrated to Professional Education. He returned to the point where it began, ten years after the Vocational Schools, to investigate possible advances, challenges and future prospects. A qualitative research was

${ }^{1}$ Doutora em Educação pela Universidade Estadual do Ceará, Professora do Instituto Federal de Educação, Ciência e Tecnologia do Ceará (IFCE), Campus Limoeiro do Norte. Ceará, CE, Brasil. e-mail: cleide.silva@ifce.edu.br

2 Doutora em Educação pela Universidade de São Paulo (2000), com estágio sandwich na Universidade de Frankfurt, Mestre em Educação pela Universidade Federal do Ceará (1995), Especialista em Ciência Política pela Universidade Federal do Ceará (1994), Graduada em Serviço Social pela Universidade Estadual do Ceará (1992). Ceará, CE, Brasil. e-mail: rejane.bezerra@uece.br 
DOI: $10.12957 /$ e-mosaicos.2019.46576

carried out, supported by Dialectical Materialism, through a case study, with interview, observation, questionnaire and document analysis. Critical Discourse Analysis was used. The results revealed Vocational Education as a watershed in Ceará High School. It was concluded that the curricular flexibility made specificities specific to the professional schools, changed the teaching professionalism and the student routine.

KeYwORDS: High school; Brazil Professionalized Program; Professional education; Project Teacher Class Director; Ceará.

\section{INTRODUÇÃO}

O Programa Brasil Profissionalizado semeou uma nova realidade para o Ensino Médio e a Educação Profissional do Ceará. Inseriu um currículo novo, alterou as condições de trabalho dos professores, proporcionou equipamentos físicos adequados, oportunizou novos materiais e formação aos gestores e professores.

Desta feita, o objeto deste estudo foi delimitado no recorte temporal pós Lei de Diretrizes e Bases da Educação Nacional (LDB) 9.394/96, fazendo uma alusão ao Decreto no 2.208/97, e, posteriormente, concentra-se no Decreto no 5.154/2004, aportando implicações diretas à educação profissional, à profissionalidade dos professores e aos processos formativos, com o fito de alcançar o Decreto 6.302/2007, de criação do Programa Brasil Profissionalizado.

O modelo de Educação Profissional desenvolvido no Programa Brasil Profissionalizado não se fez imune ao processo de globalização, contendo, portanto, características da conjuntura econômica neocapitalista, sincronizado ao sistema da produção flexível. Do mesmo modo, a política de formação desenvolvida com os gestores e professores das Escolas Profissionais, bem como a formação dos jovens cearenses no cotidiano escolar, não ficaram alheias ao referido contexto, integrando, destarte, percursos formativos de qualificação técnica destinada à preparação de mão de obra.

O presente texto objetivou investigar o impacto do Projeto Professor Diretor de Turma nas Escolas Profissionais para a Profissionalidade Docente do Ceará. O contexto cearense até o ano de 2007 ofertava somente o Ensino Médio na modalidade regular e em 2008, com a adesão ao Programa Brasil Profissionalizado, implantou o Ensino Médio integrado a Educação Profissional.

Metodologicamente, a pesquisa é de abordagem qualitativa, assentada em um Estudo de Caso, que se utilizou de entrevistas, observação, questionário e análise documental após decorridos dez anos de implantação das Escolas Profissionais no contexto cearense, para investigar possíveis avanços, desafios e perspectivas futuras. A pesquisa foi realizada em uma Escola Estadual de Educação Profissional e contou com a participação de professoras formadoras, professores diretores de turma e estudantes. Os dados foram analisados à luz da Análise do Discurso Crítico. 
Além da Introdução e das Considerações Finais, o texto está estruturados em três partes que trazem a Fundamentação Teórica, o Percurso Metodológico, os Resultados e a discussão dos dados.

\section{REFLEXÕES SOBRE ENSINO MÉDIO, EDUCAÇÃO PROFISSIONAL E PROGRAMA BRASIL PROFISSIONALIZADO}

Nos anos de 1990, precisamente no governo Itamar Franco, criaram-se as condições ideais para gestar a base jurídica que daria sustentação à política neoliberal a ser implantada no contexto brasileiro. Homologou-se em 1996, a Lei 9.394/96, de Diretrizes e Bases da Educação Nacional (LDB), com vistas à sustentação dos mecanismos legais que viabilizariam as políticas neoliberais. Vive-se a partir de então, os primeiros impactos do Decreto no 2.208, de 17 de abril de 1997. Este dispositivo regulamentou o parágrafo $2^{\circ}$ do artigo 36 e os artigos 39 a 42 da referida Lei, que estabeleceu as diretrizes e bases da educação nacional.

As implicações desse processo são complexas e exigem análises densas para a construção da crítica teórica sobre o desenvolvimento da política neoliberal. Trata-se de questões diversas que se proliferaram na educação, no trabalho e na vida social da população menos favorecida economicamente.

O Decreto no 2.208/97 aportou notáveis retrocessos à educação como um todo, como também, o desenvolvimento da Educação Profissional desarticulada da formação geral. As implicações foram imediatas: fragmentação e descontextualização dos conteúdos, aligeiramento da formação, baixo custo dos processos de ensino e aprendizagem e a legitimidade da dualidade escolar. As consequências alcançaram a desarticulação dos movimentos sociais de base, a corrosão dos direitos sociais, o sufocamento da classe trabalhadora, a competitividade e a meritocracia social. Provocaram também a inércia da massa crítica intelectual, que atuava na área educacional, comprometendo o desenvolvimento do projeto de formação humana para além do capital (FERRETTI, 2000).

Inicia-se, portanto, para o Ensino Médio um longo ciclo de forte interferência dos organismos internacionais através das políticas neoliberais deflagradas pela reforma educacional pós Lei 9.394/1996. A ampla reforma educacional anunciada pelo governo brasileiro guiava-se pelas influências de organismos supranacionais, que buscavam estabelecer novas relações entre Estado, sociedade e mercado com a finalidade de consolidar a posição hegemônica mercantilista.

Pesquisas de Frigotto (2011) asseveram que a prioridade educacional se fazia somente na ação retórica. As políticas neoliberais se desenvolviam pelo discurso oficial da modernização centrada num projeto ortodoxo, monetarista, financista e rentista. Neste sentido, a educação pública atrelada ao mercado, deixou de ser um 
DOI: $10.12957 / \mathrm{e}-\mathrm{mosaicos} .2019 .46576$

direito social e passou a um serviço mercantil.

Frigotto e Ciavatta (2003), em suas análises sobre as políticas desenvolvidas no período pós LDB, asseveram que o desenvolvimento político-econômico propalado na década de 1990 camuflou o protagonismo reformista das próprias instituições multilaterais cujos objetivos internacionais estavam articulados aos acordos regionais e nacionais e também vinculados aos interesses do mercado.

Decretou-se assim, o silenciamento de fomento a autonomia intelectual e ao pensamento crítico. A proposição do Decreto 2.208/1997 suprimiu os ideais de autonomia e sucumbiu a tentativa de construção da identidade que se tentava construir sobre a formação dos jovens brasileiros. Propagou ainda o fortalecimento das escolas privadas como instituições preparadoras de exames de vestibular, sufocando a escola pública e responsabilizado alunos e professores pelo próprio insucesso educacional.

De acordo com Frigotto (2011), dada a realidade brasileira no início dos anos 2000, tornava-se urgente a ruptura do dualismo e a melhoria da qualidade educacional com políticas de intervenção estrutural. $O$ autor assevera em sua análise sobre o aporte legal do período pós LDB, que os instrumentos guiadores da política educacional neste período priorizaram os interesses capitalistas e não as potencialidades humanas. Assim, atribui o fracasso escolar aos governos desenvolvimentistas, afirmando que as forças políticas conservadoras assumiram o poder na década de 1990 determinadas a vender o patrimônio público, aplicar as teses neoliberais na economia e fazer a reforma educacional em favor da cultura neoliberal.

O contexto brasileiro expressava a taxa de escolaridade líquida do Ensino Médio brasileiro como uma das mais baixas da América Latina, em torno de 50,9\%, o que significava um enorme desafio para a universalização do ensino. Diante do exposto, a melhoria educacional demandava investimentos nos campos econômico e político, o que ainda tem se caracterizado nos dias atuais como um desafio no sentido de fortalecer a luta contra o conservadorismo e os interesses da classe dominante (FRIGOTTO, 2011).

O Brasil registrava a $12^{a}$ posição mundial do Produto Interno Bruto (PIB) entre os países mais ricos do mundo, ao mesmo tempo em que contrastava a $63^{a}$ posição no Índice de Desenvolvimento Humano (IDH). Assim, "Essa distância entre esses dois Brasis, o pobre e o rico [...]" clamava por ações interventivas de políticas estruturais que amenizassem a exclusão (CEARÁ, 2008, p. 08).

Os dados expressavam que o Ensino Médio no Brasil atingia somente $22 \%$ da população jovem, enquanto a Argentina contabilizava $51 \%$, a Coreia do Sul em torno de $82 \%$ e os Estados Unidos chegavam a $91 \%$ (CEARÁ, 2008). A delicada situação do Ensino Médio lançou o Brasil aos piores indicadores em âmbito internacional. $O$ Programa Internacional de Avaliação de Alunos (PISA) de 2006 posicionou o Brasil em último lugar na avaliação de leitura, matemática e ciências dentre um conjunto 
DOI: $10.12957 / \mathrm{e}-\mathrm{mosaicos} .2019 .46576$

de 41 países. Nessa época, o Brasil obteve o pior nível de desempenho (VIEIRA, 2007).

No panorama nacional pairavam diversas críticas em razão de políticas que promoviam a estagnação do Ensino Médio e a dualidade educacional ocasionada pelas últimas reformas. As mudanças empreendidas até então não só mantiveram os velhos problemas do Ensino Médio como também agravaram a exclusão com os parcos resultados na aprendizagem.

Os desafios não se restringiam somente à dimensão pedagógica, mas à dimensão estrutural determinada pela contradição entre capital e trabalho. As políticas educacionais realizadas pós Lei No 9.394/1996 não favoreceram uma educação de qualidade aos que viviam da venda de sua força de trabalho (KUENZER, 2008). O baixo índice de acesso ao Ensino Médio, acrescido da distorção idade-série, além de evasão e reprovação escolar, comprometia o futuro dos jovens na faixa etária de 15 a 18 anos. As circunstâncias sinalizavam a urgência de uma política nacional que assegurasse 50 mil novas salas de aulas e a contratação de 500 mil novos professores em atendimento a demanda reprimida (CEARÁ, 2008).

Especificamente, em relação aos indicadores do Ceará, os dados do desempenho acadêmico dos estudantes cearenses, detalhados por escola e por CREDE, revelaram o histórico situacional crítico ou muito crítico. Confirma-se assim que a realidade cearense não se diferenciava da situação encontrada nos demais estados brasileiros, posto que os dados do Sistema Permanente de Avaliação da Educação Básica do Ceará (SPAECE) ratificavam o inexpressível rendimento escolar, abaixo da média nacional e da meta estadual (CEARÁ, 2008). Levando em conta os déficits educacionais, o governo do Ceará agilizou a parceria com o governo federal, assegurando o projeto de intervenção destinado à melhoria dos indicadores educacionais do Ensino Médio.

Com o passar do tempo as críticas ecoaram fortemente contra a onda de reformismo desenvolvida no Brasil diante da descontinuidade das políticas públicas e dos retrocessos educacionais (SAVIANI, 2008). A trajetória histórica de 2003 a 2011 direcionou um novo olhar sobre a crise educacional brasileira. 0 país passou a ser governado pelo presidente Luiz Inácio Lula da Silva, eleito diretamente pelo voto popular por meio do Partido dos Trabalhadores (PT).

Em 2003, a Secretaria de Educação Profissional e Tecnológica do Ministério da Educação (SETEC/MEC) organizou diversas articulações com vários segmentos sociais, por meio de fóruns, programas, projetos e políticas voltados à educação na perspectiva de expandir a Educação Profissional Integrada ao Ensino Médio.

O primeiro Seminário Nacional "Ensino Médio: Construção Política" priorizou a discussão sobre a realidade do Ensino Médio brasileiro; o segundo Seminário Nacional de Educação Profissional "Concepções, experiências, problemas e propostas" foi específico para a Educação Profissional e Tecnológica. Tais eventos deram origem ao documento publicado pelo MEC em 2004, intitulado "Proposta em 
DOI: $10.12957 / \mathrm{e}-m o s a i c o s .2019 .46576$

discussão: Políticas Públicas para a Educação Profissional e Tecnológica", como aporte teórico para as ações que o seguiram.

A abertura de novas possibilidades conjecturou-se no governo Lula com a aprovação do Decreto 5.154/2004, que revogou o Decreto no 2.208/97, retomando com isso a possibilidade de articulação entre a educação geral e a Educação Profissional. O Decreto 5.154/2004 resultou das manifestações contrárias à política de formação desenvolvida na década anterior baseada no conceito de "empregabilidade" pela via das "competências", na flexibilização dos currículos, priorizando a redução do tempo de formação dos sujeitos, dos custos e, principalmente, promovendo o esvaziamento do conhecimento para a agilidade da certificação.

O Decreto no 5.154/2004 propiciou legitimidade a publicação do Decreto 6.302/2007, que normatizou e assegurou a institucionalização do Programa Brasil Profissionalizado (PBP), aporte legal da oferta do Ensino Médio integrado à Educação Profissional em âmbito nacional, por meio de parcerias entre o governo federal e os governos estaduais para o financiamento da Educação Profissional e Tecnológica (BRASIL, 2007).

O governo federal por meio do PBP disponibilizou aos estados brasileiros apoio técnico e recursos financeiros para a construção de escolas, ampliação, reforma, aquisição de recursos materiais, mobiliário, equipamentos, laboratórios, livros, além da formação dos gestores e professores. A pujança financeira trazida pelo PBP fomentou a criação das Escolas Estaduais de Educação Profissional (EEEP), denominadas neste texto de Escolas Profissionais.

Para o Ceará, os dados do site da União destacam captação de recursos captados para investimentos na Política de Educação Profissional com vistas à expansão da oferta de Ensino Médio Integrado à Educação Profissional na ordem de $\mathrm{R} \$ 124.241 .566,92$ (Cento e vinte quatro milhões, duzentos e quarenta e um mil, quinhentos e senta e seis reais e noventa e dois centavos). Com esse aporte financeiro o Programa Brasil Profissionalizado semeou uma nova realidade para o Ensino Médio e a Educação Profissional do Ceará. Inseriu um currículo novo, alterou as condições de trabalho dos professores, proporcionou equipamentos físicos adequados, oportunizou novos materiais, laboratórios e formação para gestores e professores.

\section{Percurso metodológico}

A política de integração do Ensino Médio à Educação Profissional no Ceará formalizou-se na primeira gestão do governador Cid Ferreira Gomes (2007-2010). Coordenada pela Secretaria da Educação Básica (SEDUC), integrou a Secretaria da Ciência, Tecnologia e Educação Superior (SECITECE), Instituto Centro de Ensino 
DOI: $10.12957 / \mathrm{e}-\mathrm{mosaicos} .2019 .46576$

Tecnológico (CENTEC), para a elaboração do Plano de Ações Articuladas (PAR), como também o Plano Integrado de Educação Profissional e Tecnológica do Estado do Ceará, homologado em 2008, engajando dentre outros segmentos da sociedade civil organizada.

A presente investigação contou com um rigoroso percurso teóricometodológico a fim de garantir a cientificidade de uma possível replicação. Priorizouse o método, a orientação epistemológica, a natureza da investigação e os procedimentos metodológicos de coleta das informações que melhor se adequaram a pesquisa e a concepção materialista Histórica Dialética pela interface da Práxis Filosófica de Vázquez (2007).

O materialismo histórico desmistifica os dogmas, as relações contraditórias e as causas que determinam os acontecimentos, como também proporciona direcionamento para a emancipação, razão pela qual considera a totalidade, a especificidade e a singularidade de uma dada realidade. A Práxis Filosófica vazqueana em constante alinhamento marxista dialoga com a concepção de mundo, de homem e de sociedade em que o pensamento é reflexo da ação racional, subjetiva e interconectada ao mundo exterior e material da realidade histórica. Por isso, justifica-se a escolha, em razão do fenômeno estudado, ser caso complexo e contraditório.

A decisão pela pesquisa qualitativa também se alinhou a amplitude e a necessidade de imersão subjetiva, buscando dar conta dos sujeitos investigados e de suas relações na interação social. O alicerce marxista forneceu uma teoria sólida, conforme se evidencia no Materialismo Histórico e na Práxis Filosófica em Vázquez (2007). Nesta perspectiva, aportou-se à obra vazqueana outros fundamentos teóricometodológicos com intuito de sustentar uma análise fundamentada em princípios epistemológicos críticos em oposição aos dogmas alienantes da consciência comum. Os argumentos de análise estão apoiados na Análise do Discurso Crítico (ADC) de Fairclough (2001). A pesquisa de natureza qualitativa foi desenvolvida por meio de um estudo de caso e contou com vasto material analítico.

De acordo com Yin (2005, p. 20), "o estudo de caso é uma estratégia adequada ao se examinar acontecimentos contemporâneos" em diversas situações da vida real. Permite, portanto, a apreensão de uma realidade sob a análise em múltiplas dimensões que envolvem o caso. Desta forma, Yin (2005) propõe análise de três princípios articuláveis à variação das fontes metodológicas: a consonância do marco teórico, a manutenção de um banco de dados atualizado e o encadeamento das evidências para assegurar a precisão, a confiabilidade e a originalidade da análise.

Ainda, conforme Yin (2005) as evidências podem surgir de várias fontes distintas, dentre as quais documentos, registros em arquivos, observação direta, entrevistas, observação participante e artefatos físicos. No caso em estudo, o corpus foi extraído do material de observação, de análise documental, de entrevistas com 
DOI: $10.12957 / \mathrm{e}-\mathrm{mosaicos} .2019 .46576$

quatro professoras formadoras (SEDUC; IFCE e UECE) ${ }^{3}$ e quatro professores ${ }^{4}$ da Escola Profissional investigada. A pesquisa alcançou ainda, a aplicação de 120 questionários com estudantes dos Cursos técnicos de Agricultura, Aquicultura, Informática e Química.

\section{DE 2008 A 2018 - deZ ANOS dAS ESCOLAS PROFISSIONAIS dO CEARÁ: AVANÇOS, DESAFIOS E PERSPECTIVAS}

No ano de 2008, ocasião do lançamento das escolas profissionais, foram inauguradas vinte e cinco unidades escolares, uma matrícula de 4.091 alunos ofertando quatro cursos profissionais de nível técnico: Informática, Enfermagem, Guia de Turismo e Segurança do Trabalho, contemplando vinte municípios cearenses. Em 2009 foram entregues mais vinte e seis unidades. Decorridos dez anos da implantação, o ritmo de construção foi reduzindo em razão da escassez dos recursos financeiros disponibilizados pelo governo federal (LEITE, 2019).

Com base nos dados fornecidos pela SEDUC, até março de 2019 existem 119 Escolas Estaduais de Educação profissional em funcionamento com 52.571 alunos matriculados, ressaltando que as últimas escolas inauguradas são remanescentes de convênios firmados anteriormente com o governo federal (CEARÁ, 2019). As despesas com a aquisição de materiais, mobiliários e laboratórios estão sob a responsabilidade do tesouro estadual, haja vista a não continuidade de disponibilização de recursos por parte do governo federal. Conforme informações da Coordenadoria da Educação Profissional do Ceará houve uma estagnação dos recursos para a continuidade dos investimentos no PBP, ficando, portanto, tudo a cargo do próprio estado. Observa-se que, no lugar de novas construções, o estado tem ampliado a diversidade de cursos nas unidades existentes.

A digressão na política de integração do Ensino Médio à Educação Profissional se deu pela via dos processos formativos e contou com a investigação em uma das 119 unidades existentes. A escola foi selecionada mediante critérios técnicos, por estar localizada na região metropolitana de Fortaleza, atender ao modelo tipo padrão MEC, contar com um núcleo gestor constituído por uma diretora geral e três coordenadores pedagógicos, atendendo a 440 estudantes do Ensino Médio em tempo integral com a modalidade de Educação Profissional. Esses alunos são

\footnotetext{
${ }^{3}$ Secretaria de Educação do Estado do Ceará - SEDUC (Coordenadora das Escolas Profissionais e a coordenadora do Projeto professor Diretor de Turma - PPDT); Professora da Universidade Estadual do Ceará - UECE e uma professora do Instituto Federal de Educação, Ciência e Tecnologia do Ceará IFCE. As formadoras foram selecionadas com fundamento na técnica da imputação social (JAKOBS, 2007).

${ }^{4}$ Os professores foram selecionados em virtude dos critérios de atuar como diretor de turma; ter conhecimento ou ter participado da implantação do PPDT e das escolas profissionais. Para esse texto utilizamos codinomes para preservar a identidade dos informantes.
} 
DOI: $10.12957 / \mathrm{e}-\mathrm{mosaicos} .2019 .46576$

divididos em doze (12) turmas, distribuídas em quatro cursos técnicos: Agricultura, Aquicultura, Informática e Química.

Dos quatro cursos inicialmente ofertados, as escolas profissionais passaram a ofertar 53 cursos agrupados em 12 eixos do Catálogo Nacional de Cursos Técnicos (BRASIL, 2016), conforme informações da Coordenadoria da Educação Profissional COEDP/SEDUC (CEARÁ, 2019).

As Escolas profissionais foram introduzidas no Ceará para intervir na melhoria educacional e se reinventaram no próprio contexto econômico neoliberal. A nova proposta do Ensino Médio Integrado à Educação Profissional fundamentou-se nos princípios do Instituto de Corresponsabilidade pela Educação (ICE), por meio da Tecnologia Empresarial Sócio Educacional (TESE) ${ }^{5}$, adaptada da Tecnologia Empresarial Odebrecht (TEO) ${ }^{6}$, alicerçada na pedagogia de resultados e no modelo de competências.

Indagou-se aos participantes como se deu a Política de integração do Ensino Médio à Educação Profissional no Ceará. Umas das professoras relatou:

Num contexto extremamente complicado de muitas disputas, seja porque o próprio currículo traz muito isso, território contestável em torno da hegemonia dos projetos que se colocavam e também porque era uma experiência muito nova para o estado do Ceará. Não tinha nada que pudesse balizar, que pudesse servir como referência, era uma construção que iniciava ali e tudo teria que ser construído a partir dali (Professora Formadora - UECE).

O modelo de Educação Profissional desenvolvido no Programa Brasil Profissionalizado não se fez imune ao processo de globalização, contendo, portanto, características da conjuntura econômica neocapitalista, sincronizado ao sistema da produção flexível. Do mesmo modo, a política de formação desenvolvida com os gestores e professores das Escolas Profissionais, bem como a formação dos jovens cearenses no cotidiano escolar não ficaram alheias ao referido contexto, integrando, destarte, percursos formativos de qualificação técnica destinada à preparação de mão de obra.

A investigação permitiu evidenciar coalizões, revelou interesses antagônicos, direcionamentos de controle, estratégias e conteúdos dos processos formativos.

\footnotetext{
${ }^{5} \mathrm{~A}$ TESE é propriedade do ICE e surgiu para a aplicação na educação pública de nível médio articulada por um grupo de empresários e ex-alunos do Ginásio Pernambucano. Caracteriza-se pela incorporação de preceitos da administração e gestão de instituições privadas no âmbito da gestão pública.

${ }^{6} \mathrm{~A}$ TEO se baseia nos fundamentos éticos, morais e conceituais para a condução dos negócios e a atuação de todos integrantes da empresa Odebrecht Engenharia e Construção S.A. Foi adaptada à gestão educacional com ênfase na potencialidade humana para o alcance de metas e resultados.
} 
DOI: $10.12957 /$ e-mosaicos.2019.46576

Assim,

A gente disfarçadamente tentava fazer os cursos sem olhar só para o mercado... de um lado se fazia a matriz curricular... do outro tinha o pessoal de Pernambuco com o modelo da Educação Profissional deles... havia um grande movimento com os empresários. Esse era o nosso grande desafio. Foi bem complicado; as pessoas da escola propedêutica queriam puxar pro seu lado, as da profissional pro seu. Foram muitas reuniões, muitos debates e um longo estudo do currículo (Professora Formadora-IFCE).

As análises dos discursos ocorreram de forma textualmente orientada e no modelo tridimensional definido por Fairclough em 1999 no qual incluíra o Discurso, a Prática Discursiva e a Prática Social. O cerne da formação expressa claramente as intencionalidades formativas pelo próprio conteúdo trabalhado com professores e gestores para atuação nos processos de ensino e aprendizagem com os estudantes em sala de aula. A investigação identificou duas frentes de formação: uma fortemente demarcada no período da implantação das Escolas; outra mais alinhada aos dias atuais, centrada em três frentes, na estratégia da formação, no conteúdo e nas condições formativas.

O modelo referencial utilizado no estado do Ceará foi o do Centro de Ensino Experimental (PROCENTRO), criado em 2002 por um grupo de empresários em Recife, no estado de Pernambuco. Em 2004, o PROCENTRO incorporou a TEO, que posteriormente foi adequada e denominada TESE, com a finalidade de inovar a gestão escolar do primeiro Centro de Ensino em Tempo Integral. A experiência pernambucana foi amplamente veiculada pelos empresários como uma proposta exitosa capaz de revolucionar o Ensino Médio brasileiro no sentido de promover a superação de antigos problemas, posto que

Naquele momento havia uma corrida, um foco do próprio governo, mas não existia uma discussão que pudesse dar lastro, dar sustentação ao projeto pedagógico das Escolas. Daí as articulações da Secretaria de Educação, trazendo uma experiência incrementada em Pernambuco embasada nos pressupostos da Tese no âmbito da fundação Odebrecht [...] (Professora Formadora IFCE).

A TESE foi apresentada como uma proposta "nova" para a juventude brasileira conforme disposto em seu Manual Operacional (2005) destinado às Escolas em Tempo Integral. No entanto, os princípios formativos reproduzem fielmente a concepção educacional tecnicista desenvolvida nos anos de 1970. Trata-se de uma abordagem sistêmica de ensino que se fundamenta na teoria behaviorista da aprendizagem. Esta prática é definida por uma atuação pedagógica rígida, controlada 
DOI: $10.12957 / \mathrm{e}-$ mosaicos.2019.46576

e dirigida pelo professor. O docente é um facilitador dos processos de ensino numa perspectiva estritamente técnica e limitada. A ação docente parte de uma estratégia planejada que demanda um detalhamento de ações programadas.

Os professores da unidade de ensino defenderam o período inicial em que aconteciam as condições formativas, desde a presença física, dos espaços formativos e dos conteúdos trazidos por alguns dos professores formadores. Esta visão é condizente com uma das falas das formadoras ao citar "à época se fazia seminário nos lugares mais sofisticados possíveis, no Hotel Vila Galé, por exemplo, foi um dos espaços físicos que sediou momentos de estudos em que se discutiam os textos de vários estudiosos, como Gramsci, Marx, dentre outros" (Professora Formadora do IFCE).

Na fase atual, a formação mantém o viés da TESE avultada na proposta de competências socioemocionais. As discussões sobre as competências emocionais têm se intensificado fortemente sob o comando da classe empresarial, de forma articulada às instituições governamentais pela via das organizações não governamentais, a exemplo do Instituto Ayrton Senna, referência na parceria com os estados de Goiás e do Ceará. A fala da professora formadora da SEDUC exemplifica "[...] A partir de 2016, a SEDUC passou a desenvolver a Formação para a Cidadania e o Desenvolvimento de Competências Socioemocionais [...]". Conforme a entrevistada, em 2017 a parceira se intensificou com a realização do I Seminário Internacional de Competências Emocionais do Instituto Ayrton Senna e contou com os palestrantes Ricardo Paes de Barros, economista-chefe do referido instituto e professor do Instituto de Ensino e Pesquisa - Insper; Filip De Fruyt, psicólogo e docente na Universidade de Ghent, na Bélgica, dentre outros (CEARÁ, 2019). Conteúdo este, abordado nas respostas dos professores da Escola e acrescido da crítica pela seletividade participativa. A formação tem acontecido na própria escola no sistema de repasse, ou seja, a coordenação assiste nos Centros de Regionais de Desenvolvimento da Educação (CREDES) e repassa aos demais na própria Escola. Sobre o conteúdo das habilidades socioemocionais, apareceu uma única vez no relatos de um participante. "Ajuda através das habilidades socioemocionais, postura profissional, dentre outras" (Professor Pau-Brasil).

A pesquisa revelou que no momento atual os Professores Diretores de Turmas atuantes na Escola Profissional têm aprendido mais no dia a dia, uns com os outros, com os próprios esforços. Isto é, os professores com mais experiência compartilham suas aprendizagens com os professores novatos. A sistemática de representatividade profissional na formação parece não chegar à Escola. Perguntou-se especificamente sobre a formação voltada ao PPDT, vejamos as respostas: "Muito superficial" (Professora Seringueira); "Boa, mas precisa melhorar; no início era melhor. O Diretor de Turma precisa de formação e de orientações (Professor Jatobá); "Não há uma formação específica para o projeto" (professora Castanheira); "É o projeto que sustenta uma Escola Profissional" (Professor Pau-Brasil).

As respostas expõem pontos críticos da formação do PPDT. Nas últimas 
DOI: $10.12957 / \mathrm{e}-\mathrm{mosaicos} .2019 .46576$

décadas têm proliferado formações que mais aprisionam do que formam os professores, caracterizando-se como ações descontínuas e superficiais. Na perspectiva do discurso crítico a partir de Fairclough (2010), a sistemática da representatividade na formação docente compromete 0 aprofundamento dos conhecimentos. Uma vez que as bases da formação não são aprofundadas pelos professores, estes não conseguem desenvolver-se criticamente nos processos de ensino e aprendizagem. Assim, o desenvolvimento intelectual não encontra sentido e as aprendizagens são esvaziadas pela crítica silenciada.

Investigou-se a partir do PPDT o impacto das Escolas para a profissionalidade docente, como também para a vida estudantil. As respostas dos professores assinalaram a implantação de profundas alterações na profissionalidade docente nos aspectos relacionados aos conteúdos, carga horária, mudança de propostas, dentre outros fatores.

Os registros da observação e as respostas dos entrevistados desenharam novo cenário com implicações diretas à profissão docente, influenciando no desenvolvimento de competências relacionadas à formação, à convivência grupal e às novas práticas escolares. Estudantes e professores apontaram o PPDT como um projeto inserido pela flexibilização curricular que se sobrepôs aos propósitos da formação técnica, definido nos princípios educativos da razão e na emoção, com a premissa de desmassificação do ensino. O foco na permanência e êxito estudantil constituiu-se uma principal das principais bases apoio aos estudantes frente a nova rotina de tempo integral a partir da mediação do Professor Diretor de Turma. (CEARÁ, 2014). Vejamos as revelações dos alunos a partir das repostas coletadas no questionário aplicado. O questionário consta de quatro opções: na formação geral dos estudantes; no controle da infrequência para a melhoria do ensino e da aprendizagem; na qualificação para o mundo do trabalho e na relação/acompanhamento família e escola. Sobre o PPDT e o PDT no dia a dia: segue uma amostragem das respostas: "É um projeto criado para acompanhar de perto os alunos e ajudar no rendimento e também auxiliar nos problemas" (Arbustos$1 \mathrm{QE1} 1^{7}$ ); "É um projeto que ajuda na rotina escolar" (Ervas Rasteiras-1AE1); "É fundamental no rendimento escolar do aluno e na vida social" (Espifitas 2IE1); "orienta para a tomada de decisões no futuro" (Espifitas 2IE2).

Para Fairclough (2001), os estudantes são enunciadores e cotidianamente constroem imagens. Implicitamente, os PDTs expressam comportamentos verbais e não verbais. Fairclough (2001) destaca que o comportamento verbal e não verbal é um fenômeno intertextual, por isso, os PDT são interpretados e desenhados nos enunciados pelos estudantes. A análise aponta que a construção estudantil agregou um valor social a identidade profissional assinalada cotidianamente pelos estudantes.

\footnotetext{
${ }^{7}$ Optou-se pela preservação da identidade dos estudantes. Para a composição da sigla 1QE1, o "1" significa a primeira série do Ensino Médio; o "Q" representa o curso de Química; o "E" retrata estudante e o "1" final a numeração do informante. A mesma regra segue para os demais participantes com variação de série, curso e numeração.
} 


\section{CONSIDERAÇÕES FINAIS}

A priori, fazer a conclusão de um trabalho científico parece fácil, mas não é. Arrematar os diversos pontos de um processo científico requer alguns cuidados imprescindíveis à credibilidade das análises e da própria investigação. São muitas informações a serem reorganizadas na lógica conclusiva.

Neste artigo as análises realizadas à luz da ADC, evidenciaram que o Ceará passou a contar com uma nova forma de fazer Educação Profissional após o Programa Brasil Profissionalizado. O financiamento do Programa favoreceu a criação das Escolas Profissionais e a oferta de vagas de tempo integral. A parceria entre governo federal e estadual empreendeu uma política arrojada, demarcando um verdadeiro divisor de águas em relação ao que se tinha antes e depois da institucionalização do PBP.

O aporte financeiro do Programa propiciou uma nova realidade para os professores e gestores e um novo currículo para os estudantes do Ensino Médio. As informações coletadas e analisadas apontaram avanços na matrícula, desaceleração do ritmo de construção de novas unidades, preocupação com a estagnação dos investimentos financeiros por partes do governo federal, sinalizando possíveis limitações e desafios para a manutenção do ensino.

A pesquisa evidenciou ainda, coalizão de interesses formativos, dois tipos de formação e a crítica epistemológica, novos elementos da profissionalidade docente do Professor Diretor de Turma (PDT) e o alcance da perspectiva estudantil em relação à nova rotina. Nas respostas dos estudantes, ganhou destaque o acolhimento e a orientação por parte do PDT, desnudaram valores de escuta, sensibilidade e atitudes dialogáveis atribuídas aos profissionais do Projeto, confirmando o fortalecimento de vínculos entre o PDT e os estudantes por meio dos olhares de ambos.

\section{REFERÊNCIAS}

BRASIL. Lei no 9.394/1996 de 20 de dezembro de 1996. Diretrizes e Bases da Educação Nacional. Centro de Documentação e Informação. Brasília: Edições Câmara, 1996.

BRASIL. Decreto $n^{\circ}$ 2.208/97. Regulamentação do $\S 2^{\circ}$ do art. 36 e os artigos 39 a 42 da Lei no 9.394, de 20 de dezembro de 1996, que estabelece as Diretrizes e Bases da Educação Nacional. Brasília, 1997. 
DOI: $10.12957 / \mathrm{e}-\mathrm{mosaicos} .2019 .46576$

BRASIL. Decreto No 5.154/2004. Regulamentação do § $2^{\circ}$ do art. 36 e os artigos. 39 a 41 da Lei no 9.394, de 20 de dezembro de 1996, que estabelece as Diretrizes e Bases da Educação Nacional. Brasília, 2004.

BRASIL. Decreto No 6.302/07. Instituiu o Programa Brasil Profissionalizado. Brasília: Ministério da Educação/MEC, 2007.

BRASIL. Programa Ensino Médio Inovador. Documento Orientador para adesão. Ministério da Educação. Secretaria de Educação Básica. Diretoria de Currículos e Educação Integral. Coordenação Geral de Ensino Médio. Brasília: MEC, 2016.

CEARÁ. Plano Integrado de Educação Profissional e Tecnológica do Estado do Ceará. Fortaleza: SEDUC, 2008.

CEARÁ. Manual de Orientações das ações do Professor Diretor de Turma. Secretaria da Educação/SEDUC. Fortaleza: Coordenadoria de Cooperação com os Municípios Coordenadoria de Cooperação com os Municípios, 2014.

CEARÁ. Secretaria de Educação do Estado do Ceará - SEDUC (2019). Portal da Educação Profissional. Disponível em: https://educacaoprofissional.seduc.ce.gov.br/. Acesso em 07 ago. 2019.

FERRETTI, Celso João. Mudanças em sistemas estaduais de ensino em face das reformas no Ensino Médio e no Ensino Técnico. Educação \& Sociedade, ano XXI, no 70, Abril/2000.

FAIRCLOUGH, Norman. Critical Discourse Analysis: The critical studyof language. 2. ed. Harlow: Routledge, 2010.

FAIRCLOUGH, Norman. Discurso e mudança social. Brasília: EdUNB, 2001.

FRIGOTTO, Gaudêncio. Perspectivas sociais e políticas da formação de nível médio: avanços e entraves nas suas modalidades, Educ. Soc., Campinas, v. 32, n. 116, p. 619-638, jul.-set. 2011.

FRIGOTTO, Gaudêncio; CIAVATTA, Maria. Educação Básica no Brasil na década de 1990: subordinação ativa e consentida à lógica do mercado. Educ. Soc., Campinas, vol. 24, n. 82, p. 93-130, abril 2003.

JAKOBS, Günther. A imputação objetiva no Direito Penal. Trad. André Luís Callegari. 2. ed. São Paulo: RT, 2007.

KUENZER, Acácia Zeneida. Formação de professores para a educação profissional e tecnológica: perspectivas históricas e desafios contemporâneos (Mesa-redonda). p. 19-40 In: INEP. Formação de Professores para Educação Profissional e Tecnológica: 
DOI: $10.12957 / \mathrm{e}-\mathrm{mosaicos} .2019 .46576$

Brasília: 26, 27 e 28 de setembro de 2006. - Brasília: Instituto Nacional de Estudos e Pesquisas Educacionais Anísio Teixeira, 2008.

LEITE, Maria Cleide da Silva Ribeiro. O projeto professor diretor de turma e a profissionalidade docente no contexto da educação profissional. Tese de Doutorado. Universidade estadual do Ceará - UECE, Fortaleza, 2019.

MANUAL OPERACIONAL - Modelo de Gestão, Tecnologia Empresarial Sócio Educacional (TESE). Uma nova escola para a juventude brasileira (2005).

SAVIANI, Dermeval. Política educacional brasileira: limites e perspectivas. Revista de Educação PUC-Campinas, Campinas, n. 24, p. 7-16, junho 2008.

VIEIRA, Sofia Lerche. Política(s) e Gestão da Educação Básica: revisitando conceitos simples. RBPAE- v.23, n.1, p. 53-69, jan./abr. 2007.

VÁZQUEZ, Adolfo Sánchez. Filosofia da Práxis. São Paulo: Expressão Popular, 2007.

YIN, Roberto K. Estudo de caso: Planejamento e Métodos. Trad. Daniel Grassi. 2. ed. Porto Alegre: Bookman, 2005.

Recebido em 10 de novembro de 2019

Aceito em 04 de dezembro 2019

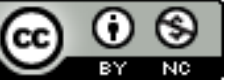

A e-Mosaicos Revista Multidisciplinar de Ensino, Pesquisa, Extensão e Cultura do Instituto de Aplicação Fernando Rodrigues da Silveira (CAp-UERJ) está licenciada com uma Licença Creative Commons - Atribuição-NãoComercial 4.0 Internacional.

Os direitos autorais de todos os trabalhos publicados na revista pertencem ao(s) seu(s) autor(es) e coautor(es), com o direito de primeira publicação cedido à e-Mosaicos.

Os artigos publicados são de acesso público, de uso gratuito, com atribuição de autoria obrigatória, para aplicações de finalidade educacional e não-comercial, de acordo com o modelo de licenciamento Creative Commons adotado pela revista. 